\title{
La guerra biológica en la conquista del nuevo mundo. Una revisión histórica y sistemática de la literatura
}

\author{
ALEXIS DIOMEDI P. ${ }^{1}$
}

\section{The biological warfare in the conquest of the new world.}

A historic and systematic review of the literature

Five centuries ago the European invaders arrived to the New World. They carried with them what turned out to be their main allies in the conquest of the continent: smallpox, measles and influenza viruses. In an attempt to recompose the process of dissemination of such diseases, a systematic review of the biomedical and historical literature was performed, to investigate how the Spaniards first, and the British later, used mainly smallpox to undertake a biological warfare against the American Indians, which eventually meant the biggest population catastrophe that America has never suffered in all its history.

Key words: Biological warfare, History, American indians, Smallpox.

Hace 510 años junto al conquistador europeo arribaron al nuevo continente un conjunto de enfermedades infecciosas a las que la población nativa del continente jamás había sido expuesta. El efecto de su diseminación en la población amerindia susceptible fue aniquilante y devastador. Se trata fundamentalmente de virosis de transmisión respiratoria, como viruela, influenza y sarampión ${ }^{1}$ que, producto del "encuentro de poblaciones" en un trasiego de población casi unidireccional y mayoritario desde Europa hacia América, favorecieron la supremacía de un pequeño grupo de exploradores sobre vastos dominios como fueron el imperio azteca y el incaico de ese entonces. Al respecto la introducción de numerosa población africana, a través del mercadeo de esclavos, tuvo decisiva influencia en la propagación de estas "nuevas" enfermedades en la naciente colonia ${ }^{1}$.

En efecto, cuando los españoles arribaron a México en 1518, la población aborigen ascendía a unos 25 millones de habitantes ${ }^{2-5}$, diez años después había disminuido a 16,8 millones $^{4}$, para 1568 a 3 millones $^{6}$ y para 1618 a sólo 1,6 millo- nes ${ }^{2,3}$. Los territorios andinos de Sudamérica albergaban unos 6 a 8 millones de nativos en el periodo prehispánico ${ }^{4}$, fundamentalmente concentrados en el Tahuantinsuyu o Imperio Inca, estimándose que al sur de Panamá la población prehispánica total alcanzaba a algo menos de 20 millones de habitantes (Figura 1). Al norte de México, se estima que la población amerindia norteamericana alcanzaba también a unos $20 \mathrm{mi}-$ llones al inicio de la colonización ${ }^{3}$, población que también decayó producto de las epidemias originadas desde el arribo de los colonizadores puritanos hacia 1560.

Así, desde la llegada de Colón, los europeos y sus infecciones, unos 56 millones de aborígenes americanos -prácticamente $95 \%$ de la población precolombina- habrían sido exterminados por los agentes biológicos, la destrucción de sus culturas ancestrales y los abusos de la conquista ${ }^{2,6-8}$.

Entendemos por guerra biológica ${ }^{9}$ el uso con fines hostiles de microorganismos vivos, cualquiera sea su naturaleza, o del material infectante o tóxico derivado de ellos, destinados a causar enfermedad o muerte al hombre, animales o plantas.

\footnotetext{
Unidad de Infectología, Hospital Del Salvador.

Unidad de Cuidados Intensivos, Instituto Nacional del Tórax.
} 


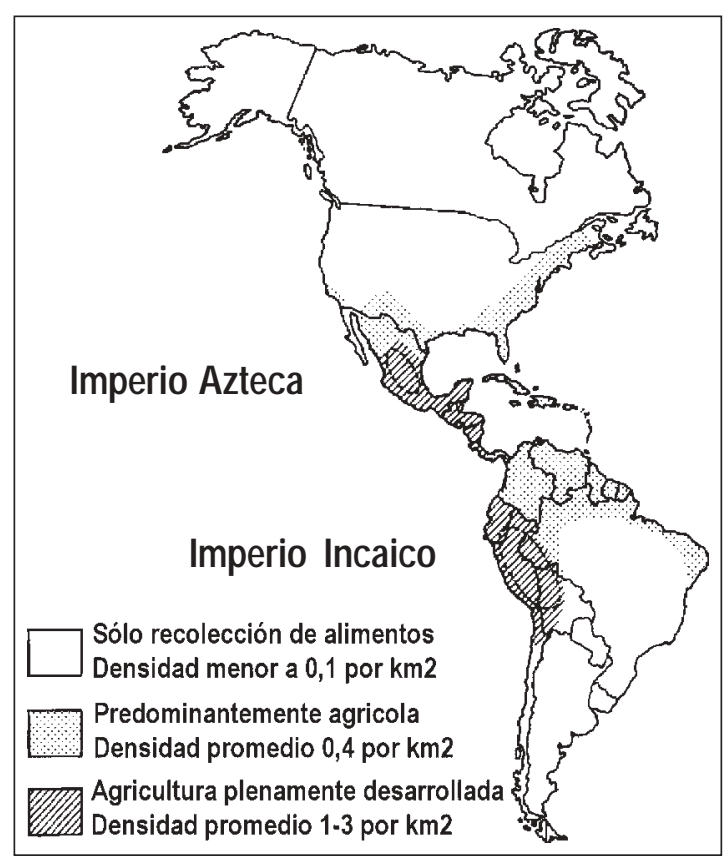

Figura 1. Desarrollo agrícola y densidad poblacional de las Américas a la llegada de los españoles. (Modificado de Fennet -5-).

Si bien parece ser una definición sencilla, históricamente puede ser difícil distinguir entre lo que pudiera ser la transmisión natural o antropogénica de una enfermedad infecciosa.

Por otro lado, el uso de agentes biológicos como estrategia de conquista y/o dominación no deja de plantearse como método atractivo en el contexto de la expansión europea en América. Los historiadores clásicos, sobretodo los iberoamericanos, tienden a exculpar de cualquier intencionalidad a los conquistadores en el desastre geno-ecológico arriba detallado. Indudablemente nos encontramos ante un fenómeno que podríamos rotular como el sesgo del vencedor, que distorsiona el relato de los eventos a lo largo de toda la historia humana, sobretodo cuando las culturas subyugadas han sido imposibilitadas de conservar o difundir documentación detallada de tales sucesos.

Con el propósito de conocer -con las salvedades ya comentadas- los antecedentes históricos del probable uso de armas biológicas en la invasión europea del nuevo mundo, se plantea bajo la estrategia de revisión sistemática de la literatura biomédica, la recolección de documentación significativa y verosímil al respecto.

\section{Material y Método}

Se realizó una búsqueda en PubMed, Medline y LILACS, de artículos publicados entre enero de 1966 y noviembre de 2002, utilizando el criterio título de argumento médico mayor (MESH) "biological warfare/history", adicionalmente se combinaron el texto simple "biological warfare", con "american indians", "smallpox" y "history". En el análisis de aquellas publicaciones relevantes se identificaron citas biográficas pertinentes, siendo incluidas en la recopilación de la literatura revisada. La recopilación de literatura se realizó a través de bibliotecas médicas nacionales y latinoamericanas (BIREME), publicaciones electrónicas en línea y solicitud postal a los autores según fuese necesario.

\section{Resultados}

Se identificaron 74 artículos publicados en la búsqueda primaria, la mayoría de ellos de autores anglosajones (64 en inglés). Se recopilaron otras 37 referencias secundarias, muchas de las cuales corresponden a ensayos históricos, tratados de medicina militar, historia de la medicina e historia ambiental, como también diversas publicaciones de Internet. En total se consultaron casi 111 referencias directas o indirectas sobre el uso de agentes biológicos como método de guerra a lo largo de la historia del hombre, de las que se seleccionaron aquellas que contenían información referente a la conquista del continente americano a partir del siglo XVI.

De este modo se identificaron tres momentos en la guerra de conquista americana donde se habría utilizado principalmente la viruela, como forma de mermar la resistencia de las poblaciones aborígenes ante el ejercito invasor, cuyos detalles se bosquejan a continuación.

La conquista de México y el imperio azteca ${ }^{4,6}$. Hacia 1517, Cuba era el principal establecimiento español en América. Entre ese año y el siguiente el Gobernador Diego de Velásquez envió dos expediciones hacia el golfo de México, a cargo de Francisco Hernández de Córdoba y Juan de Grijalva respectivamente. Las expectativas fueron promisorias, por lo que en 1519 Velásquez comisionó a Hernán Cortés (1485-1547) para una extensa expedición al continente (Figura 2). Las ordenes originales sólo contemplaban la exploración y el comercio, no la conquista. Sin embargo, Cortés se estableció en Veracruz (abril 22, 1519), donde se rebeló del mando de Velásquez, reconociendo sólo en la corona española una dependencia ${ }^{6}$.

Gracias a una estrategia de alianzas matizada con crueles matanzas de poblaciones indígenas 


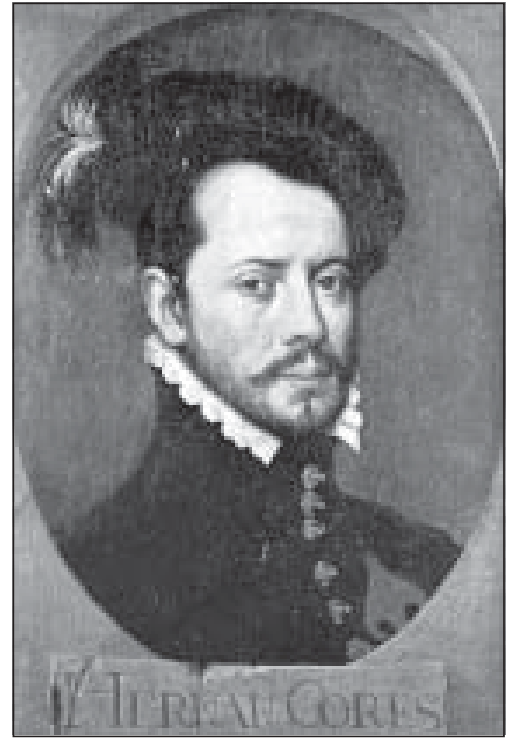

Figura 2. El Conquistador de México, Hernán Cortés.

tiranizadas por el dominio azteca, Cortés logró alcanzar la capital imperial Tenochtitlán el 8 de noviembre de 1519 (Figura 3), donde el tlatoani Moctezuma, quien consideraba a los españoles enviados de los dioses, les recibió como huéspedes, colmándolo de tributos. Luego Moctezuma fue tomado prisionero por Cortés, quien debió enfrentar sucesivamente en mayo de 1520 , la expedición de Pánfilo de Narváez, destinada a reducir su empresa y apresarlo, y la revuelta de los aztecas, producto de la Matanza del Gran Templo, posterior a lo cual fue asesinado Moctezuma. Como consecuencia de este último evento Cortés fue expulsado de Tenochtitlán, perdiendo cerca de dos tercios de su ejercito (unos 500 hombres); este episodio es conocido como la Noche Triste del 30 de junio de $1520^{6}$.

Finalmente, Cortés doblegó al ejército de Narváez, entre cuyos refuerzos se incluyó un esclavo africano que padecía viruela. El episodio es relatado por el fraile Toribio de Benavente, Motolinia-10: “...que ya entrado en esta Nueva España el capitán y gobernador Dn. Fernando Cortés con su gente, al tiempo que el capitán Pánfilo de Narváez desembarcó en esta tierra, en uno de sus navíos vino un negro herido de viruelas, la cual enfermedad nunca en esta tierra se había visto, y a esta sazón estaba toda esta Nueva España en extremo muy llena de gente, y como las viruelas se comenzasen a pegar a los indios, fue entre ellos tan grande enfermedad y pestilencia mortal en toda la tierra, en los otros la proporción fue menor ..." (Figura 4).

Casi un año después, el 31 de mayo de 1521, Cortés inició el asedio final de Tenochtiltlán (Figura 5), habiéndose propagado extensamente la epidemia de viruela, que había diezmado a los aztecas, dando cuenta también del sucesor de Moctezuma, el tlatoani Cuitláhuac. No obstante bajo la guía del joven príncipe Cuauhtémoc, la resistencia indígena se extendió por casi ochenta días de sitio, el 13 de agosto de 1521 la ciudad de México-Tenochtitlán cayó en manos de Hernán Cortés. Era el fin del imperio azteca ${ }^{4}$.

La caída del imperio incaico ${ }^{6,11,12}$. Francisco Pizarro (1476-1541) (Figura 6), al tanto de los rumores de la existencia de un imperio rico y populoso en las tierras del "birú" - nombre indígena de un río del norte de las costas colombianas, posteriormente llamadas "Perú"- organizó hacia 1524 junto al sacerdote Hernando de Luque y a Diego de Almagro la empresa de conquista de "las tierras de sur" 6,12 .

En las sucesivas exploraciones emprendidas desde Panamá (Figura 7), en 1525 y 1527 desembarcaron varias veces en Tacámez, Jama, Portoviejo, Isla Puna y Tumbes (Figura 7). Entre escaramuzas asaltos y encuentros pacíficos con los nativos, confirmaron la existencia del imperio

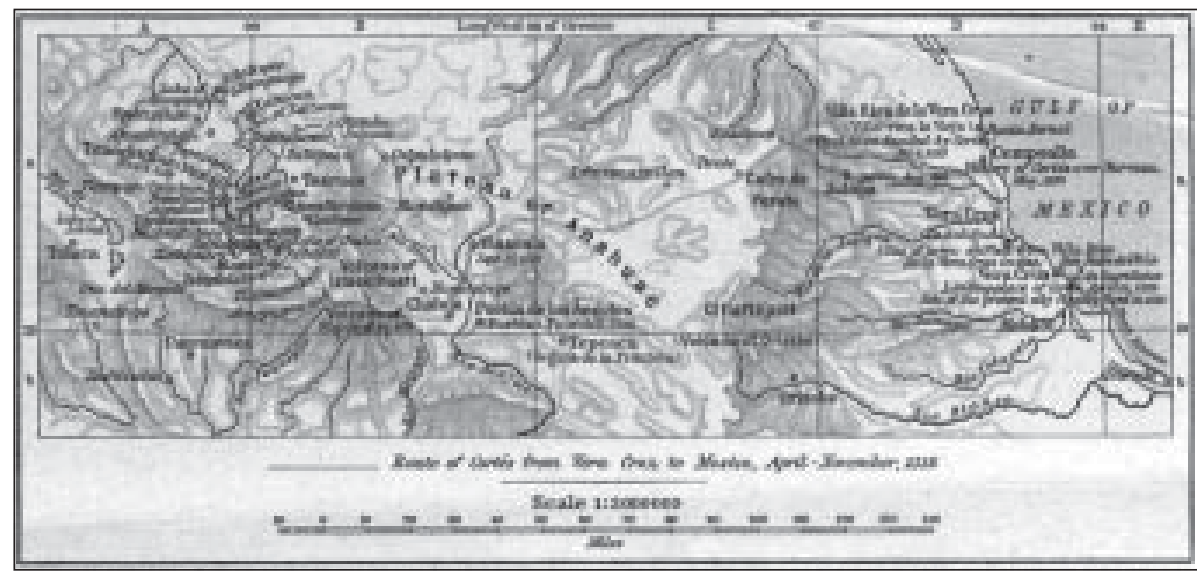

Figura 3. Ruta de la expedición de Cortés en 1519. Modificado de http://www.lib.utexas. edu/maps/historial/ sheperd/conquestme xico151912.jpg 


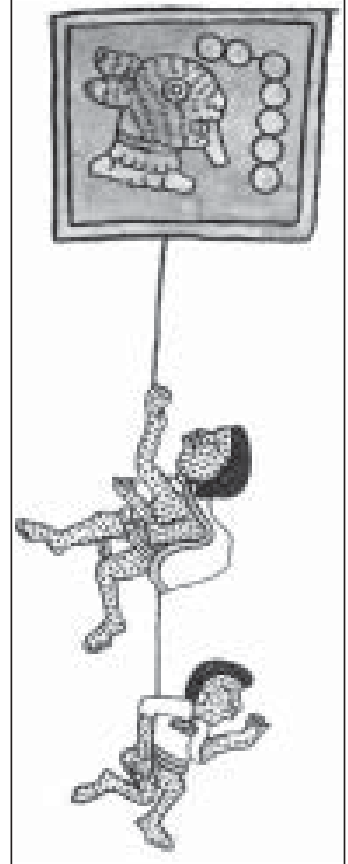

Figura 4. Representación de enfermos con viruela (México 1538) -5-.
Inca o Tahuantinsuyu. Las observaciones empíricas de sus capitanes, entre los que se encontraba su hermano Hernando, habían correlacionado la viruela con su enorme mortandad entre la población indígena, razón por la cual solían enviar por delante de sus tropas a soldados o esclavos portando lanzas con lienzos impregnados con secreciones obtenidas de enfermos de virue$1 \mathrm{l}^{13}$; además, cuando levantaban sus campamentos abandonaban las prendas de los enfermos de viruela o las ofrecían a los indígenas locales ${ }^{14,15}$; Así la idea fue obtener futuras victorias militares al diseminar esta enfermedad entre la población incaica.

Hacia enero de 1531, Francisco Pizarro habiendo conseguido la autorización del rey Carlos I, emprendió la conquista definitiva del Perú, con un reducido ejercito de 166 hombres y 25 caballos. Para su fortuna encontró un imperio en plena guerra fraticida, luego de que el inca Huaina Capac primero y su sucesor designado Ninah

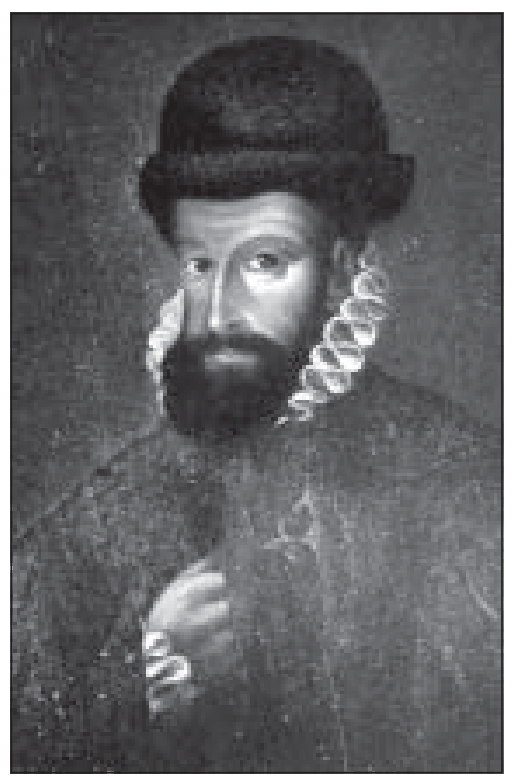

Figura 6. Francisco Pizarro, conquistador del Perú.

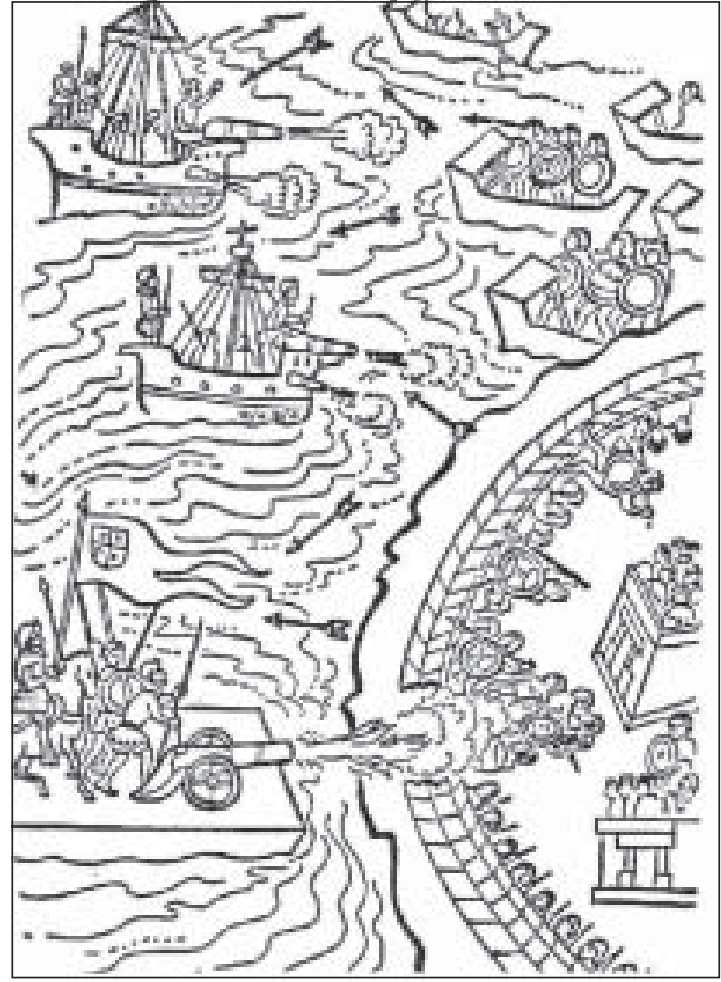

Figura 5. El sitio a Tenochtitlán. Grabado Siglo XVI.

Cuyuchi luego, fallecieran, alrededor de 1527, víctimas de la epidemia de viruela que asolaba al Tahuantinsuyu. Atahualpa recién se alzaba con la victoria sobre su hermano Huáscar, al que había ejecutado, por lo que su mandato como inca todavía no conseguía una solidez necesaria como para soportar la arremetida española ${ }^{6,12}$.

En Cajamarca en noviembre de 1532, Pizarro y su reducido destacamento mediante una sorprendente estratagema, emboscaron al estático

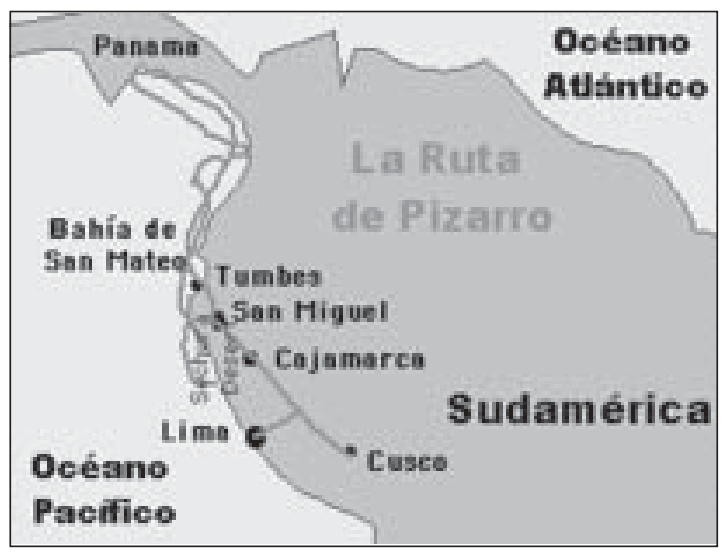

Figura 7. Ruta exploratoria de Francisco Pizarro. Según datos de Terán -12-. 


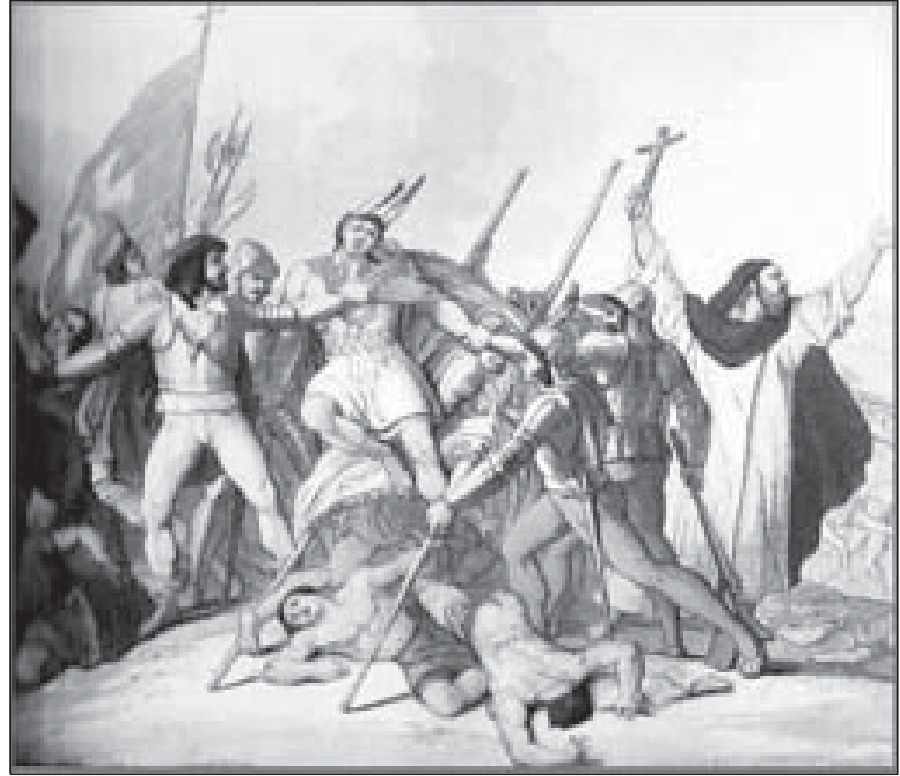

Figura 8. La captura de Atahualpa.

ejercito inca de casi cuarenta mil soldados, capturando al emperador Atahualpa (Figura 8). En julio de 1533, luego de pagar un cuantioso rescate en oro, Atahualpa fue ejecutado y en su lugar los españoles instalaron a un monarca títere, Manco Inca ${ }^{12}$.

La guerra franco india y la rebelión de Pontiac de $1763^{16}$. Hacia 1760 el líder de la tribu Ottawa Bwon-Diac (1720-1769), que por accidentes de traducción es conocido históricamente como Pontiac, declaró la guerra a los invasores franceses e ingleses apostados en la región de los Grandes Lagos y el Mediooeste norteamericano; ello le permitió conseguir el armisticio y una alianza estratégica con Francia en 1763.

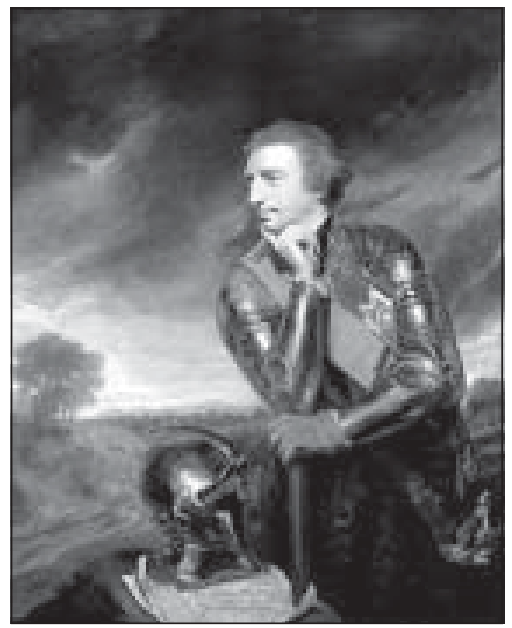

Figura 9. Sir Jeffery Amherst. Modificado de Fenn -16-.
Sin embargo, persistían los abusos de las fuerzas británicas, bajo el mando de Sir Jeffery Amsherst (1717-1797) (Figura 9) ${ }^{16}$. El 27 de abril de ese año en una asamblea de tribus, Pontiac concretó una coalición de doce tribus, entre los que se incluían los Ottawa, Chippewas, Shawnee, Mingo y Delaware. De este modo, el 7 de mayo se inició el asedio al Fuerte Detroit. Entre el 16 y el 29 de mayo nueve de los once fuertes británicos habían caído, manteniéndose sitiados los fuertes Pitt y Detroit (Figura 10).

El Fuerte Pitt, ubicado en la confluencia de los ríos Allergheny y Monongahela, se encontraba bajo el mando del capitán Simeón Ecuyer, quien reportaba su situación al Coronel Henry Bouquet en Filadelfia. Éste a su vez informaba al General Amherst. La resistencia era eficaz pero hacia el 16 de junio la viruela había brotado entre los sitiados. En un memorando sin fecha Sir Jeffery Amherst, pregunta al coronel Bouquet, "¿Podría idearse el enviar la viruela a esas tribus de indios descontentos?". La contestación fechada en julio 13 fue: "Voy a tratar de inocularlos con algunas cobijas que caigan en su poder, teniendo cuidado de no contraer yo mismo la enfermedad". El 16 de julio Amherst respondía "Hará bien con tratar de inocular a los

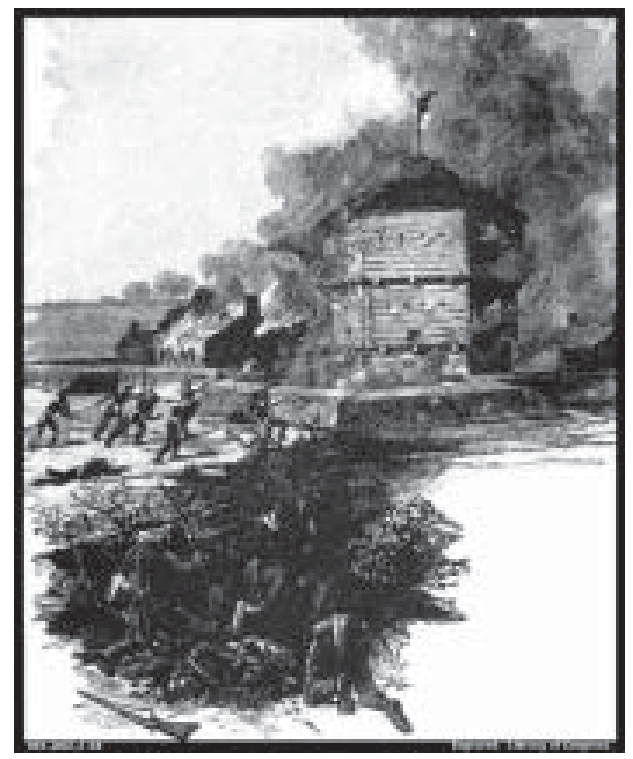

Figura 10. El sitio del Fuerte Pitt durante la rebelión de Pontiac. 


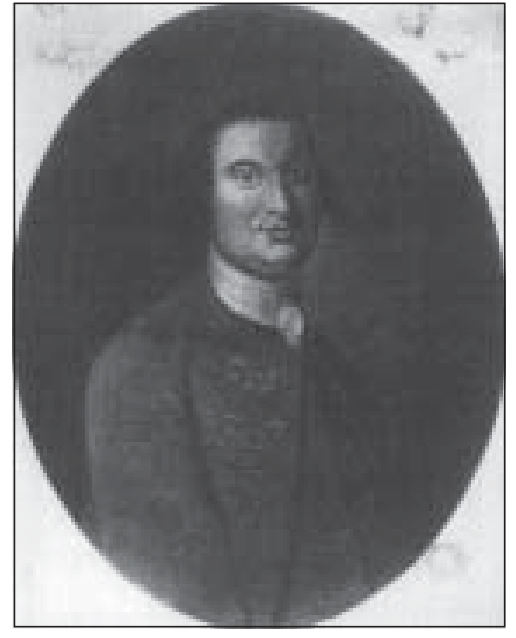

Figura 11. Coronel Henry Bouquet. Modificado de Fenn -16-

indios por medio de mantas, como también trate de utilizar cualquier otro método que pueda servir para extirpar esa aborrecible raza" 16 .

A esas alturas, el 24 de junio Bouquet (Figura 11) había recibido a dos representantes Delaware Corazón de Tortuga y Mamaltee, quienes instaron a los ingleses a abandonar el Fuerte Pitt, a lo que obviamente éstos se negaron. Los indios solicitaron entonces pertrechos para su viaje de retorno, lo que aprovechó Bouquet para darles dos mantas y un pañuelo de seda obtenidos del dispensario de enfermos con viruela. "Esperamos que tengan los efectos deseados" escribiría luego en su diario William Trent, un soldado inglés del Fuerte Pitt. Aparentemente el subalterno habría obrado antes de recibir instrucciones de Amherst, frente a lo cual seguramente el General no habría presentado reparos.

Peter MacLeod ${ }^{16}$, sugiere que el ejercito británico venía practicando sistemáticamente la propagación de viruela entre los indios desde 1755, a propósito del brote que diezmó en 1757 a los Potawatomis, a la sazón aliados de los franceses, sus adversarios en la colonización de Norteamérica. De allí se entiende esta "anticipación" del coronel Bouquet.

En los años siguientes al incidente, la epidemia cundió entre la población indígena de las inmediaciones del Fuerte Pitt. En abril de 1764, Gershom Hicks, un explorador capturado por los Shawnee y Delaware un año antes, ya libre relataba “...que la viruela ha estado generalizada y furiosa entre los indios desde la primavera pasada y que treinta o cuarenta Mingos, Delaware y algún Shawneese han muerto de viruela desde entonces, que esto todavía sigue entre ellos"16,17. La epidemia se extendió hasta fines de 1765; esta cronología es muy sospechosa y coincide estre- chamente con la distribución de artículos infectados por los colonos del Fuerte Pitt.

\section{Discusión}

Con posterioridad a septiembre de 2001, la sensibilidad científica y general se ha volcado con mayor interés hacia la temática de la guerra biológica y el uso de agentes infecciosos al servicio del terrorismo. El brote estadounidense de ántrax postal ${ }^{18,19}$ ha forzado la revisión y discusión del tema con menor o mayor angustia en cada foro científico, diplomático o social de nuestro globalizado orbe ${ }^{20}$. De vuestros errores aprenderéis, dicta nuestra conciencia colectiva, que por cierto nos obliga a revisar el empleo de la guerra biológica en nuestra historia cultural de occidente. Con este fin, parece relevante tratar de mirar con imparcialidad nuestra historia continental para centrar opiniones a la hora del análisis.

La empresa europea de exploración y conquista de América no parece responder al altruismo como leit motiv, sino que a la pedestre ambición de señoríos y riquezas de los hidalgos de la época ${ }^{6}$, por cierto algo alejados de la ilustración renacentista y más cercanos al fervor y la intransigencia religiosa. Sin embargo, hubo notables excepciones justamente entre clérigos de la época ${ }^{1,6,10}$, gracias a los cuales existen testimonios escritos sobre las costumbres de los aborígenes $^{1,6,7}$, de las enfermedades que los atacaron $^{1,2,7}$, de los excesos de los conquistadores y sus consecuencias ${ }^{1-3,6,7}$. Hoy esto permite indirectamente estructurar una revisión al respecto.

Las armas biológicas empíricamente formaban parte de las estrategias guerreras del medioevo europeo. En 1422 el ejército lituano catapultaba cadáveres y excrementos a los defensores de Carolstein (Austria) ${ }^{20}$, los españoles en 1495, a su vez, entregaban vino contaminado con sangre de leprosos a sus adversarios franceses ${ }^{21}$. Por lo anterior, el traslado de estas tácticas al nuevo mundo no debe extrañar, pues los líderes de la conquista se formaron en arte de la guerra luchando contra sus vecinos.

Curiosamente es la misma viruela, protagonista de esta historia, la que hoy erradicada del mundo, lo asecha con mayor terror, pues el mundo entero se asimila a los aborígenes precolombinos, susceptibles a este letal y escondido Poxviridae. No extraña, por tanto los cuestionamientos de la comunidad médico científica ${ }^{22-25}$ en torno a la necesidad de reintroducir campañas de vacunación masiva en E.U.A. y Europa. Por de pronto 
las tropas europeas y americana ya reciben tal inmunización.

En suma, las evidencias expuestas denotan el trágico significado de la invasión europea sobre legendarias culturas precolombinas. Cuidadosamente evitamos usar el término genocidio, pues por un lado, esta revisión no esta exhaustivamente concebida para extraer tal conclusión y por otro lado -como se expone en la introducción- el beneficio de la duda impone mesura al momento de juzgar personajes y épocas pretéritas.

\section{Resumen}

Hace cinco siglos arribaron al Nuevo Mundo los invasores europeos junto a los que serían sus mayores aliados en la conquista del continente, la viruela, el sarampión y la influenza. En un intento por recomponer el proceso de diseminación de tales enfermedades, se realizó una revisión sistemática de la literatura biomédica e histórica, para investigar cómo los españoles primero, y luego los británicos, utilizaron fundamentalmente a la viruela para realizar una guerra biológica contra los indios americanos, lo que a la larga significó la mayor catástrofe poblacional que jamás haya sufrido América en toda su historia.

\section{Bibliografía}

1.- Cordero del Campillo M. Las grandes epidemias en la América colonial. Arch Zootec 2001; 50: 597-612.

2.- Diamond J. Lethal gift of livestock. En Guns, Germs and Steel. WW Norton \& Company 1999. Cáp 11: 195-214.

3.- Ligon B L. Smallpox: Its history and reemergence as a weapon of biological warfare. Semin Pediatr Infect Dis 2001; 12: 71-80.

4.- Fennet F, Henderson D A et al. The history of smallpox and its spread around the world. En Smallpox and its eradication. OMS Suiza. 1988. Cáp 5; 209-43.

5.- Barquet N, Domingo P. Smallpox: The triumph over the most terrible of the Ministers of Death. Ann Intern Med 1997 October 15; 127: 635-42.

6.- Marby D J. The Conquest. En Colonial Latin America. Cáp. 3: 36-70. Disponible en http://historicaltextarchive. com/latin/colonial.pdf. Accedido el 17/12/02.

7.- López Gómez R. De epidemias, Conquistadores e Indígenas. Disponible en www.ihnca.edu.ni/Histori_no $\% 20$ Cont/Histori_I/037_epidemias_indígenas.htm. Accedido el 18/01/02.
8.- Trupin R. Smallpox: Diseases associated with biological warfare. Disponible en: http://www. nursingceu.com/ NCEU/courses/smallpox/index.htm. Accedido en 30/ $12 / 02$.

9.- Organización de Naciones Unidas. Convención de Armas Biológicas. 1972.

10.- Benavides, Fray Toribio de. Historia de los indios de Nueva España. The Cortés Society, Berkeley 1950. Citado en Fennet F. Smallpox and its eradication. OMS Suiza 1988: 1380.

11.- Diamond J. Collision in Cajamarca. En Guns, germs and steel. WW Norton \& Company 1999. Cáp 3: 6789.

12.- Terán Najas R. La conquista del Tahuantinsuyu. En Conquista Española e inicios de la época Colonial El siglo XVI. Ecuador; raíces del presente. Disponible en http://www.dlh.lahora.com.ec/paginas/his/paginas/ historia29.htm. Accedido el 26/12/02.

13.- Aranda Anzaldo A. Los Virus: problemas de un concepto en evolución. De En la frontera de la vida: los virus. Disponible en http://lectura.ilce.edu.mx:3000/ sites/ciencia/volumen2/ciencia3/071/htm/sec_19.htm. Accedido el 26/12/02.

14.- U.S Army Medical Research Institute of Infectious Diseases. Medical Management of Biological Casualties Handbook. 4th Edition. Fort Detrick, Frederick, (M D). $2001 \mathrm{Feb}$; 9-12. Disponible en: http://www. usamriid.army.mil/education/bluebook.html. Accedido el $30 / 11 / 02$.

15.- Eitzen E M, Tkafuji E T. Historical overview of biological warfare. En Medical Aspects of Chemical and Biological Warfare. Textbook of Military Medicine 1997. Cáp 18: 415-23.

16.- Fenn E A. Biological warfare in eighteenth-century North America: Beyond Jeffery Amherst. J Am Hist 2000; 1552-80.

17.- Noah D L, Huebner K D et al. History and threath of biological warfare and terrorism. Emerg Med Clin North Am 2002; 20: 255-71.

18.- Jernigan J A, Stephens S A et al. Bioterrorism realted inhalational Anthrax: The first 10 cases reported in the United States. Emerg Infect Dis 2001; 7: 933-44.

19.- Bartlett J G, Inglesby T V, Borio L. Management of Anthrax. Clin Infect Dis 2002; 35: 851-8.

20.- Katona P. The history of bioterror and biowarfare. Buss Brief Glob Health 2002; 3: 1-2.

21.- Arizona Departament of Health service. History of biowarfare and bioterrorism. Disponible en: http://www. hs.state.za.us/phs/edc/edrp/es/ bthistor $2 . h t m$ accedido el 20/06/02

22.- Drazen J. Smallpox and bioterrorism. N Engl J Med 2002; 346: 1262-3.

23.- Veenema T G. The smallpox vaccine debate. Am J Nurs 2002; 102 (9): 33-8.

24.- Bozette $\mathrm{S}$ A. A model for smallpox vaccination policy. N Engl J Med 2003; 348 (5): 416-25.

25.- Blendon R J, Des Roches C M, Benson J M, Herrmann R J, Taylor-Clark K, Weldon K J. The public and the smallpox threat. N Engl J Med 2003: 348 (5): 42632 .

Correspondencia a:

Alexis Diomedi Pacheco

Email: adiomedip@terra.cl 